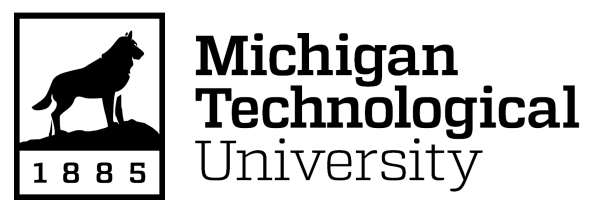

Michigan Technological University Digital Commons @ Michigan Tech

\title{
Environmental change and potential impacts: applied research priorities for Alaska's North Slope
}

\author{
B. Streever \\ BP Exploration Inc., Anchorage \\ R. Suydam \\ North Slope Borough Department of Wildlife Management \\ J. F. Payne \\ North Slope Science Initiative in Anchorage \\ Robert Shuchman \\ Michigan Technological University \\ R. P. Angliss \\ NOAA Fisheries, Alaska Fisheries Science Center
}

See next page for additional authors

Follow this and additional works at: https://digitalcommons.mtu.edu/mtri_p

Part of the Environmental Sciences Commons

\section{Recommended Citation}

Streever, B., Suydam, R., Payne, J. F., Shuchman, R., Angliss, R. P., Balogh, G., Brown, J., Grunblatt, J., Guyer, S., Kane, D. L., Kelley, J. J., Kofinas, G., Lassuy, D. R., Loya, W., Martin, P., Moore, S. E., Pegau, W. S., Rea, C., Reed, D. J., Sformo, T., Sturm, M., Taylor, J. J., Viavant, T., Williams, D., \& Yokel, D. (2011). Environmental change and potential impacts: applied research priorities for Alaska's North Slope. Arctic, 64(3), 390-397. http://dx.doi.org/10.14430/arctic4137

Retrieved from: https://digitalcommons.mtu.edu/mtri_p/48

Follow this and additional works at: https://digitalcommons.mtu.edu/mtri_p

Part of the Environmental Sciences Commons 


\section{Authors}

B. Streever, R. Suydam, J. F. Payne, Robert Shuchman, R. P. Angliss, G. Balogh, J. Brown, J. Grunblatt, S. Guyer, D. L. Kane, J. J. Kelley, G. Kofinas, D. R. Lassuy, W. Loya, P. Martin, S. E. Moore, W. S. Pegau, C. Rea, D. J. Reed, T. Sformo, M. Sturm, J. J. Taylor, T. Viavant, D. Williams, and D. Yokel 
ARCTIC

VOL. 64, NO. 3 (SEPTEMBER 2011)

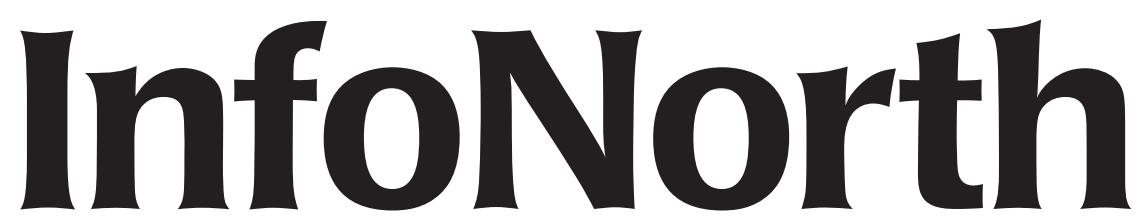

\title{
Environmental Change and Potential Impacts: Applied Research Priorities for
}

\section{Alaska's North Slope}

\author{
by B. Streever, R. Suydam, J.F. Payne, R. Shuchman, R.P. Angliss, G. Balogh, J. Brown, J. Grunblatt, S. Guyer, D.L. Kane, \\ J.J. Kelley, G. Kofinas, D.R. Lassuy, W. Loya, P. Martin, S.E. Moore, W.S. Pegau, C. Rea, D.J. Reed, T. Sformo, M. Sturm, \\ J.J. Taylor, T. Viavant, D. Williams and D. Yokel
}

\section{INTRODUCTION}

$\mathrm{T}$ The North Slope of Alaska is the vast area north of the crest of the Brooks Range (Fig. 1). Its land base encompasses $231000 \mathrm{~km}^{2}\left(89000 \mathrm{mi}^{2}\right)$, an area roughly the size of Minnesota, most of which is wetland habitat underlain by permafrost and part of which contains the largest operating oil fields in the United States. The nearshore and offshore waters of the Chukchi and Beaufort seas add another $295000 \mathrm{~km}^{2}\left(114000 \mathrm{mi}^{2}\right)$ and hold what may be the largest undeveloped oil reserves remaining in the United States. The region is home to an abundant and diverse array of fish, wildlife, and plants, resources that support the vibrant subsistence culture of about 6000 Iñupiat Eskimos. The caribou herds that summer on the North Slope are an important food resource for Iñupiat communities, as are some native plants, bowhead whales, beluga whales, four species of ice seals, and walruses living in the Beaufort and Chukchi seas. Further, Alaska's North Slope is at the forefront of global climate change, with an increase in mean annual temperature of about $1^{\circ} \mathrm{C}$ per decade in Barrow, Alaska (ACRC, 2008).

Federal, state, and local agencies manage the biotic and abiotic resources of the North Slope to maintain fish and wildlife populations and their habitats while also allowing energy development. The laws and regulations applied by government agencies managing the North Slope are rigorous, complex, and often controversial.

Appropriate management requires information that can be gained only through applied research. We provide a brief history of applied research on the North Slope, introduce the North Slope Science Initiative (NSSI) as an organization tasked with improving the coordination of science across the region, and posit applied science priorities that are essential for successful and informed management.

\section{HISTORY OF NORTH SLOPE APPLIED SCIENCE}

The earliest attempts to understand the North Slope region undoubtedly occurred when Iñupiat people and their predecessors shared information immediately relevant to their survival (Chance, 1990). Much later, a tradition of science grew from work initially undertaken during mapping expeditions, such as that of Rochfort Maguire and Dr. John Simpson during their sojourn near Barrow from 1852 to 1854 (Maguire, 1988). This tradition grew during the First International Polar Year in 1882-83 and through Diamond Jenness's anthropological studies during the 1913 Karluk expedition (Jenness, 1957). The presence of oil seeps led to establishment of the Naval Petroleum Reserve Number 4 in 1923. Exploratory drilling for oil and gas in the Alaskan Arctic started during World War II, and the Office of Naval Research established what would eventually become the Naval Arctic Research Laboratory (NARL) in Barrow in 1947 (Reed, 1958; Norton, 2001a). By 1948, a Scientific Advisory Board had been established for NARL, and nine research projects were underway, including work sponsored by multiple government agencies (Schindler, 2001). Over the decades, Barrow became a center for research activity, including ice island research, field studies across the North Slope, and the establishment in 1970 of the International Biological Programme's Tundra Biome project funded by the National Science Foundation (NSF). Following transfer of NARL to the Ukpeagvik Iñupiat Corporation, the Barrow Environmental Observatory (BEO) was established and subsequently zoned as a scientific research district. The Barrow Arctic Science Consortium was established in 1995 to promote science in the region, integrate scientists with the local community, and assist with management of the BEO.

To the southeast, adjacent to the TransAlaska Pipeline, in 1975 the National Science Foundation and the University of Alaska established the Toolik Field Station, which has hosted an Arctic Tundra Long-Term Ecological Research Program for freshwater and terrestrial field studies since the late 1980s. To the east of the pipeline lies the Arctic National Wildlife Refuge, where wildlife and wilderness studies began in the 1950s and continue into the present.

The discovery of economically recoverable oil in 1968 about $240 \mathrm{~km}(150 \mathrm{mi})$ east of Barrow and the subsequent development of oilfields spawned efforts to collect baseline data and to assess environmental impacts. Research 


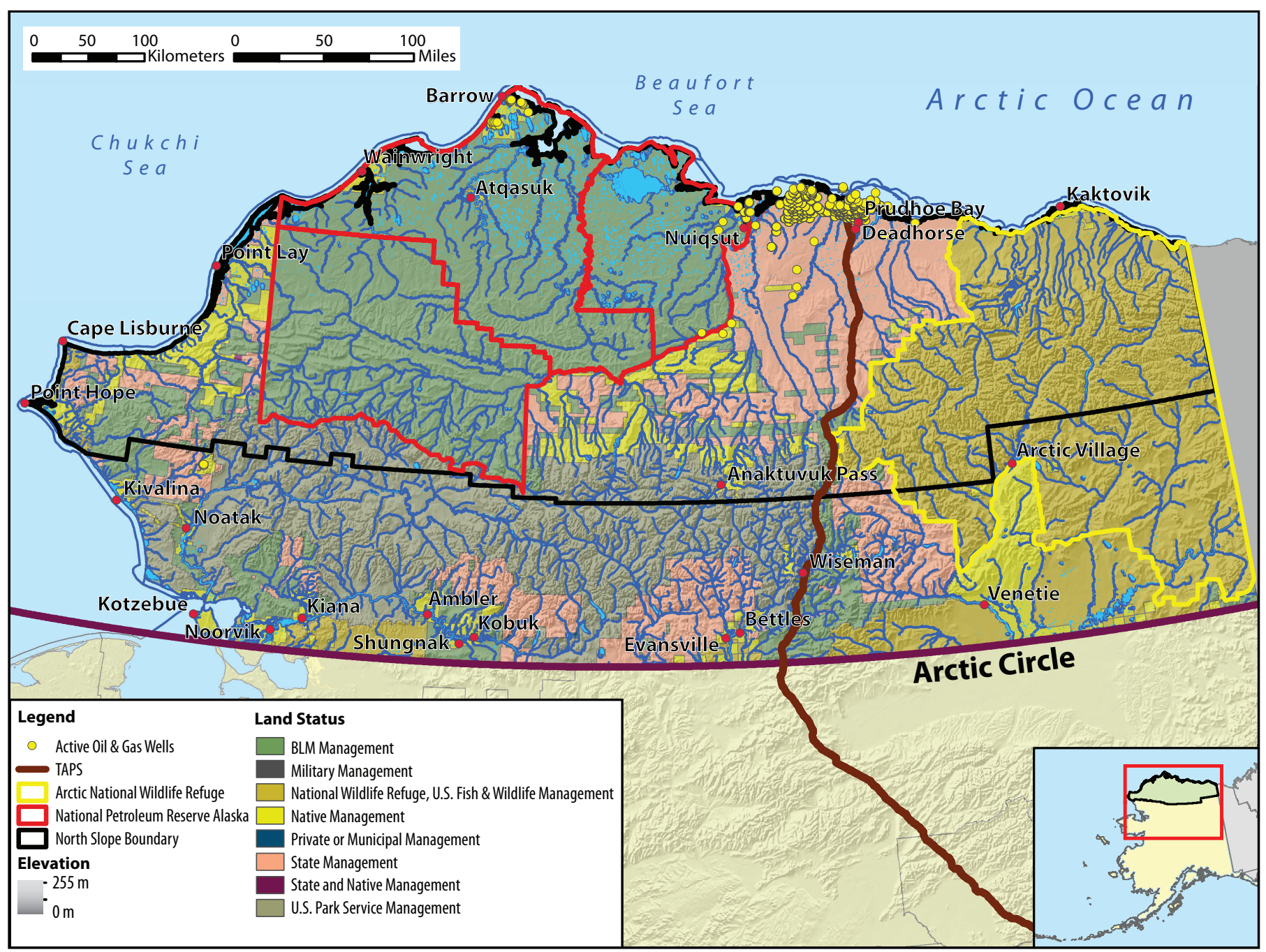

FIG. 1. The North Slope of Alaska.

was supported by various government agencies, private companies, and nonprofit organizations, but communication between these groups was often limited. Nevertheless, attempts to integrate science across disciplines occurred. For example, in the 1970s the U.S. Department of the Interior and Department of Commerce collaborated on the Outer Continental Shelf Environmental Assessment Program, an integrated marine and coastal field research program relevant to management needs (NOAA, 1978). Over time, this work evolved into the ongoing Environmental Studies Program of the Bureau of Ocean Energy Management, Enforcement, and Regulation (formerly the Minerals Management Service) and led to the production of multiple long-term data sets in coastal oceanography, biology, and social systems.

A number of book-length reviews have summarized work relevant to managers (e.g., Truett and Johnson, 2000; Norton, 2001b; NRC, 2003). These publications and other efforts promoted the benefits of an integrated, crossdisciplinary approach to science in terrestrial and marine environments.
In the last decade, several efforts to enhance coordination of applied, management-oriented Arctic science were initiated. In 2004, the Alaska Ocean Observing System began with a mission of improving the ability to detect change in marine ecosystems. In 2009, the Department of the Interior initiated an Arctic Landscape Conservation Cooperative as well as an Alaska Climate Science Center. In 2010, the National Oceanic and Atmospheric Administration proposed a National Climate Service that will include an Arctic section. Additional programs include the interagency Study of Environmental Arctic Change and the National Science Foundation's Arctic Observing Network.

All of these groups are tasked, to some degree, with fostering cooperative and intergovernmental approaches to the scientific understanding of North Slope ecosystems. The role of each of the current efforts is not clearly delineated, but the groups are working together and attempting to share data and information tracking systems, as well as striving to limit duplication of effort and to advance relevant science in the interest of best management practices. 


\section{THE NORTH SLOPE SCIENCE INITIATIVE AND THE ISSUE PAPERS}

Recognizing the need for enhanced coordination of applied science, federal, state, and local governments collectively formed the North Slope Science Initiative (NSSI) in 2001. The NSSI was formally authorized under the Energy Policy Act of 2005 (Section 348), with a broad legislative mandate to implement efforts to coordinate applied science needs relevant to resource managers on the North Slope. Its membership comprises 14 management entities (see Appendix).

The organizational structure of the NSSI allows for direct interaction between an oversight group staffed by high-level agency executives, an internal advisory group staffed by experienced agency personnel, and an external advisory group staffed by Iñupiat elders and scientists from universities, nonprofit organizations, and industry. This external advisory group, called the Science Technical Advisory Panel (STAP), is a 15-member committee established under the Federal Advisory Committee Act, making it independent of direct agency supervision. The NSSI issues an annual report to Congress through the Department of the Interior (www.northslope.org).

Soon after its formation, the NSSI asked the STAP to summarize issues important to North Slope management (Table 1). Broad topics were identified by agency executives, and questions and specific issues related to each broad topic were developed by experienced agency regulators and scientists. Working through an iterative process that combined input from agencies with information and opinions from external subject-matter experts, the STAP developed the issue papers. The first 13 of these issue papers were released to the public in late 2009 (see http://www.northslope.org/).

\section{PRIORITIES FOR NORTH SLOPE APPLIED RESEARCH}

\section{Priorities for Individual Issues}

Each of the issue papers provided recommendations for future applied research likely to be relevant to managers, but the papers were written independently of one another. After reviewing the issue papers, the NSSI Oversight Group asked the STAP to develop a prioritized list for future applied research and to assess how various issues might be related to one another.

As an initial step toward prioritizing applied research, the STAP collectively and by consensus assigned each issue (with the exception of "weather and climate," which was addressed separately) to one of three "state of knowledge" categories:

- issues that are reasonably well understood and for which research is sufficient to address most current management questions;
- issues that are less well understood and require additional research and monitoring to address management questions; and

- issues that are poorly understood and require substantial additional research and monitoring to address management questions.

Importantly, most of the issues are interdependent to some degree. For example, changes in active layer thickness above permafrost will likely result in changes to hydrology, which in turn will affect vegetation, and through vegetation, caribou and some bird populations. A conceptual model was developed displaying these issues and their interconnectedness (Fig. 2).

In addition, the amount of time needed to generate meaningful results was estimated. For example, meaningful results from restoration experiments, permafrost studies, and assessment of vegetation change will require at least 10 years because of the slow growth of plants and the slow response of permafrost. To consider "time to meaningful results," the STAP collectively and by consensus estimated the number of years (in 5-year increments to a maximum of 20 years) likely needed to move a topic from "requires substantial additional research" to "requires additional research," or from "requires additional research" to "research is sufficient" (Fig. 2).

Because some forms of research are much more expensive than others, "state of knowledge" and "time to meaningful results" categorizations should not be interpreted as suggesting funding levels. For example, "vegetation change" and "migratory birds" were both categorized as requiring additional research, but at least some aspects of vegetation change can be studied using remote sensing techniques with limited field validation, whereas migratory bird studies require substantial field efforts. In addition, a categorization of "research is sufficient" was not meant to justify a reduction in funding. Even the best researched issues require an ongoing investment in monitoring. After considering information on relationships between issues, the state of knowledge for each issue, and the estimates of time to meaningful results, the STAP prioritized the top three most pressing applied research topics for each issue (Table 1).

\section{Overarching Priorities}

Throughout development of the issue papers and during prioritization of applied research topics, five broadly applicable overarching priorities emerged: (1) systematic assessment of the range of potential development scenarios for 20 years into the future in a manner that will contribute to refinement of specific research priorities; (2) systematic assessment of the range of potential climate scenarios for 20 years into the future in a manner that will contribute to refinement of specific research priorities; (3) enhanced and well-organized collection of climate and weather data across the North Slope in a manner that will facilitate 
TABLE 1. The North Slope Science Initiative issues and associated "top three" applied science priorities identified by the Science and Technical Advisory Panel.

\begin{tabular}{llll}
\hline \hline Issue & Priority 1 & Priority 2 & Priority 3
\end{tabular}

Weather and climate

Changing sea ice conditions

Coastal salinization

Coastal and riverine erosion

Increasing marine activity

Fire regime

Contaminants

Hydrology and lake drying

Permafrost (including active layer) • Increase permafrost monitoring

Vegetation change

Caribou

Migratory birds

Marine mammals and their prey

Ecological restoration

Fisheries

Social impacts on representative landscapes

- Inventory and assess existing meteorological stations and perform gap analysis

- Collect sea ice data at spatial and temporal scales relevant to users and modelers

- Investigate the effect of increased salinity on vegetation

- Inventory and make broadly available all coastal imagery

- Understand future scenarios of marine activities

- Monitor recovery following tundra fires

- Monitor levels to detect change in air, water, soil, and biota

- Develop a stream gauge network complemented by meteorological stations

- Expand monitoring for vegetation change

- Inventory data, improve availability, and improve coordination of future data collection

- Improve monitoring before, during, and after development

- Increase knowledge of marine mammals, their prey, habitat use, impacts, and harvest, with emphasis on listed species

- Develop a systematic long-term research program, recognizing

- Develop an understanding of subsistence use in past and present.

- Coordinate and review all research involving North Slope residents as human subjects time needed to obtain results
- Pool resources from multiple funding entities to install and maintain new stations to fill gaps

- Study the fate and effects of oil spills

- Develop models of coastal salinization

- Generate accurate and groundtruthed baseline maps for selected areas

- Develop standard methods of impact assessment, especially underwater sound measurement methods

- Complete land-cover mapping to facilitate understanding of change

- Evaluate toxicity levels and monitor contamination in subsistence resources

- Develop remote-sensing technologies to facilitate mapping

- Develop remote-sensing technologies to facilitate mapping

- Inventory and evaluate existing vegetation plot data

- Develop understanding of seasonal range use and harvests (subsistence and sport)

- Inventory key data and improve availability

- Increase long-term studies that integrate information on marine mammals, their prey, and the environment

- Develop seeding methods using sedges commonly found on the North Slope

- Develop a single, accessible database on local fish abundance and distribution

- Improve methods for inclusion of local and traditional knowledge in monitoring and research of social and ecological systems
- Develop a database that integrates output from stations with existing national archives

- Study oil spill response in broken ice conditions

- Understand the impact on tundra of ice roads built with saline water

- Instrument the coastline with wind and wave sensors

- Increase broad availability of existing data

- Evaluate fire return intervals

- Improve understanding of fate and effects, especially from discharges to broken ice

- Use local knowledge in planning and assessment studies

- Inventory existing data and improve its availability

- Complete the North Slope land cover map

- Improve communications between researchers, managers, and stakeholders

- Improve understanding of impacts from spills, especially in broken ice and ice leads

- Understand the cumulative effects from human activities, including underwater sound

- Develop a clear understanding of rehabilitation trajectory during at least 20 years of growth

- Implement long-term studies on fish, their habitat, and their prey capable of differentiating between changes from natural and anthropogenic causes

- Implement systematic studies of the implications of future oil and gas development activities on North Slope communities livelihoods and well being 


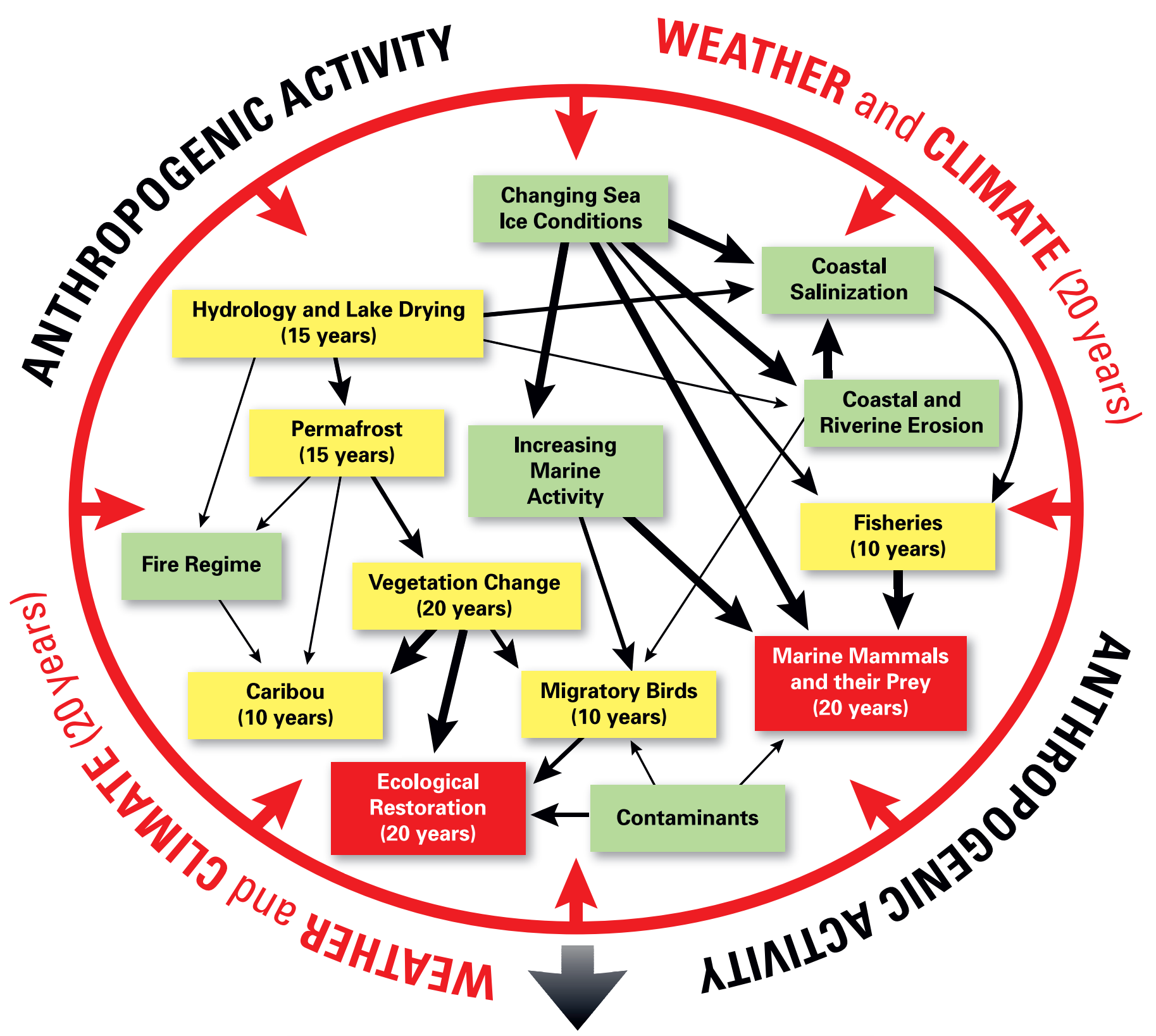

\section{Social Impacts (10 years)}

FIG. 2. Sixteen issues or research topics relevant to the management of the North Slope and their influence on one another. All are potentially affected by climate change and anthropogenic activity (i.e., development). Social impacts, which affect both local people and the intrinsic value of intact ecosystems to people well removed from the Arctic, are influenced by all the other issues. The strength of relationships is suggested by the thickness of arrows. Green represents topics for which research is sufficient to satisfy most management questions; yellow topics are less well understood and require additional research support; and topics in red are poorly understood and require substantial additional research. For topics in yellow and red, parentheses show the estimated time needed (assuming reasonable funding support for research) to move a topic up to the next knowledge level.

improved regional climate modeling, verification of climate models, and application of data in research projects; (4) regional coordination of existing long-term monitoring projects; and (5) renewed and systematic efforts to improve communication among managers, residents, and scientists through initiation of frequent "place-based" workshops.
Potential Development Scenarios: An understanding of the estimated size, location, and intensity of plausible development activities in the foreseeable future, defined here as the next 20 years, is important for prioritizing and implementing temporally and spatially appropriate research and monitoring. Because of many uncertainties, projecting 
future development scenarios will need to encompass a range of possibilities, from the "least" to the "most" new development. Both onshore and offshore development should be considered, and energy development, commercial shipping through ice-free routes, tourism, mining, commercial fishing, road construction, military activities, and other forms of development should be included.

Three realities must be addressed when considering development scenarios. First, because of changing economic conditions and the age of the two largest North Slope oilfields, future scenarios based on linear projections of past development rates will be of no value because future developments will not employ the same designs used in the past or follow the same progression. Second, while no one entity has the expertise needed to responsibly consider development scenarios on its own, by bringing together expertise from the oil industry, the regulatory community, the nonprofit community, the Iñupiat community, and others, it should be possible to consider a range of development scenarios responsibly. Third, an initial projection of a range of development scenarios should not be viewed as a static model; instead, it should be systematically revised every three to five years to optimize its usefulness in the planning of applied research.

Potential Climate Scenarios: While it is clear that the Arctic is warming, there is likely to be fine-scale spatial and temporal variation in this warming pattern that will be important to managing resources or activities on the North Slope (Martin et al., 2009). Setting science priorities properly will require downscaling of climate models in a way that facilitates understanding of potential ecological and physical impacts at various spatial scales of interest to managers (e.g., at the scale of watersheds, not continents) in the next 20 years.

It is not enough to downscale models that produce only average temperatures and precipitation. The spatial and temporal variability in temperature and precipitation, plus likely changes in wind directions and speeds, summer rains, snowpack thickness and water content, timing of freeze-thaw events, erosion, and other dynamic environmental parameters need to be modeled in order to optimize applied research prioritization.

Resources such as the circumpolar Arctic Climate Impact Assessment (ACIA, 2004) and North Slope Specific Wildlife Response to Environmental Arctic Change ("WildREACH") (Martin et al., 2009) have been useful, but climate change science cannot yet offer firm projections at local and sub-regional scales across the North Slope. A systematic review of advances in climate modeling is needed, as well as discussion of how modeling results may provide useful information about potential changes or impacts likely to be experienced by fish, wildlife, and habitats. Such a review should occur every three to five years as a way of ensuring that North Slope applied research provides the most relevant and recent information to resource managers and decision makers.
Climate and Weather Data: Meteorological data collected at adequate spatial and temporal scales are necessary for the development and validation of models underlying climate scenarios. However, the existing meteorological network on the North Slope of Alaska is haphazard at best. Individual stations are operated by myriad groups and agencies, are often short-lived, frequently use dissimilar instrumentation, and are generally at low elevations along the coast (in villages or in oilfields). There is a need to better distribute stations, which will require installation and maintenance of unmanned stations in extreme environments. In addition to the challenge of the harsh environment itself, a successful network of meteorological stations must address the costs of access, provision of power for real-time transmission of data and images, and potential wildlife damage to the instruments. There is also a need to install meteorological stations where they can complement other data collection efforts assessing variables such as stream flow, snowpack conditions, active-layer thickness, permafrost thermal state, gas fluxes, and wildlife movements.

One way forward, as recommended in the NSSI issue paper on weather and climate, is through a staged process involving (a) inventory of all stations currently in place, regardless of their capabilities; (b) assessment of the flexibility of design in existing stations to determine if modifications in design and deployment are possible; (c) canvassing of various end users to define clearly what information is needed; (d) development of a gap analysis to understand exactly what data or information is missing; and (e) pooling of resources to support an integrated network. This process should be overseen by a small working group of data collectors and end users. Because cost has been the main obstacle to development and maintenance of a spatially distributed meteorological network, it is imperative to have the participation, cooperation, and collaboration of all land- and water-management organizations.

Coordination of Long-term Monitoring: Despite the broad availability of a number of long-term monitoring reports, many of the NSSI issue papers recognized the need for additional long-term monitoring. Long-term monitoring-defined here as monitoring that has occurred for at least 10 years and is likely to be continued through the foreseeable future-requires exceptional commitment on the part of funding organizations. Monitoring must account for a highly variable environment, a warming climate, and anthropogenic stressors that affect the rates and pathways through which many components of the Arctic ecosystem interact. The involvement of North Slope communities in ecological monitoring through residents' observations and understanding of change, in partnership with scientists, may provide a useful way to achieve stronger integration and a richer understanding of emergent conditions.

In many cases, two or more monitoring programs assessing the same variables may use different methods that make comparisons difficult or impossible. For instance, plant surveys using quadrats produce different results than plant 
surveys using line transects, so that comparison of apparently similar summary statistics may be problematic. While adoption of standard protocols may seem beneficial, it does not acknowledge the underlying reasons for different protocols, such as differing research objectives or logistical constraints. Therefore, where possible, the means of comparing results from data collected using different methods should be developed. Similarly, on any one project, protocols may change over time, making comparisons across time difficult or impossible. As an example, changes over time in quadrat size or changes in plant identification skills make assessment of ecological changes difficult. The degree to which methods change over time must be understood, and if necessary, a means of allowing comparisons across time must be developed.

Moving beyond individual variables, the absence of integration hinders understanding of cause and effect. For example, failure to coordinate across topics and across temporal and spatial scales makes it impossible to correlate factors such as rainfall and grazing. Although to date no single report has summarized the key results of long-term monitoring projects from across the North Slope, reports such as Neff (2010) and Douglas et al. (2002) suggest the value of a coordinated effort and the possibility of data integration.

Improving Communication among Managers, Residents, and Scientists: Information relevant to North Slope management agencies is multidisciplinary, and collectively the amount of information available is, by any standard, overwhelming. As a result, it may be tempting for specialists to work within their discipline, in relative isolation from other disciplines. However, a clear need exists for sharing information among disciplines in a way that makes it accessible to resource managers and local residents. Furthermore, successful sharing of information among managers, residents, and scientists requires communication that is dependent on trust relationships across cultural boundaries.

One tool for improved communication could be the broad use of tracking sheets describing proposed and ongoing studies and monitoring projects. Another is a onestop information exchange, such as the NSSI Data Catalog and Project Tracking System (http://www.northslope.org).

Other approaches are needed to enhance oral communication. The annual Alaska Marine Science Symposium and the Western Arctic Caribou Herd Working Group meeting provide good examples of sharing information, but many other issues could benefit from enhanced information sharing. One approach is initiation of smaller place-based conferences or workshops - that is, events that bring together researchers, managers, and stakeholders with different backgrounds and different areas of expertise to encourage communication across specialties, such as the recent "Science, Natural Resources, and Subsistence in Alaska's Arctic Lands and Waters" meeting held in March 2011 in Barrow, Alaska.

\section{CONCLUDING REMARKS AND A WAY FORWARD}

Research is, in part, an entrepreneurial endeavor, with proposals competing for often scarce resources on the basis of intellectual merit. However, research on applied problems - including problems related to management of the North Slope-progresses most rapidly when resources are strategically deployed to enable cooperation, collaboration, and coherent development of relevant information. Research proposals assessed on the basis of carefully considered management needs are most likely to provide results that are of immediate value to managers.

Coordination of research should not be equated with control of research. The role of coordination is to help managers and local residents understand what applied research can realistically offer, to help scientists understand what managers and local residents need, and overall to reduce unwanted or unneeded redundancy while advancing complementary efforts. The suggestions outlined here may seem obvious when laid out in a systematic manner and in the context of the NSSI issue papers. However, the current reality of prioritization and funding of scientific research on the North Slope and the degree to which it is useful to managers and local residents suggest that what seems obvious in retrospect may not be obvious at all. If acted upon, the suggestions proposed here will lead to a step change in the way applied science is done on the North Slope of Alaska and, importantly, will dramatically increase the value of this science.

\section{DEDICATION}

This paper is dedicated to the late Iñupiat elders Arnold Brower, Sr., and Warren Matumeak, both past members of the North Slope Science Initiative's Science Technical Advisory Panel.

\section{ACKNOWLEDGEMENTS}

The authors acknowledge the valuable insights of the North Slope Science Initiative's Oversight Group members. The authors are also grateful for the many comments, additions, and insights provided by agency staff and external subject-matter experts. Lastly, recognizing that this paper would not have been possible without the support of their employers, the authors as a group applaud their employers for supporting this unique collaboration between government, the private sector, and the nonprofit sector.

\section{REFERENCES}

ACIA. 2004. Arctic climate impact assessment: Impacts of a warming Arctic. Cambridge: Cambridge University Press.

ACRC (Alaska Climate Research Center). 2008. Monthly time series data: Barrow, AK. http://climate.gi.alaska.edu/Climate/ 
Location/TimeSeries/Barrow.html. Fairbanks: Geophysical Institute, University of Alaska.

Chance, N.A. 1990. The Iñupiat and Arctic Alaska: An ethnography of development. New York: Holt, Rinehart and Winston.

Douglas, D.C., Reynolds, P.E., and Rhode, E.B., eds. 2002. Arctic Refuge Coastal Plain Terrestrial wildlife research summaries. U.S. Geological Survey Biological Science Report USGS/ BRD/BSR-2002-0001. http://alaska.usgs.gov/BSR-2002/usgsbrd-bsr-2002-001.

Jenness, D. 1957. Dawn in Arctic Alaska. Chicago: University of Chicago Press.

Maguire, R. 1988. The journal of Rochfort Maguire, 1852-1854: Two years at Point Barrow, Alaska, aboard HMS Plover in the search for Sir John Franklin. 2 vols. Edited by J. Bockstoce. London: The Hakluyt Society.

Martin, P.D., Jenkins, J.L., Adams, F.J., Jorgenson, M.T., Matz, A.C., Payer, D.C., Reynolds, P.E., Tidwell, A.C., and Zelenak, J.R. 2009. Wildlife response to environmental Arctic change: Predicting future habitats of Arctic Alaska. Report of the Wildlife Response to Environmental Arctic Change (WildREACH): Predicting Future Habitats of Arctic Alaska Workshop, 17-18 November 2008. Fairbanks, Alaska: U.S. Fish and Wildlife Service. $138 \mathrm{p}$.

Neff, J.M. 2010. Continuation of the Arctic Nearshore Impact Monitoring in the Development Area (cANIMIDA): Synthesis, 1999-2007. OCS Study BOEMRE 2010-032. Prepared by Neff \& Associates LLC for the U.S. Department of the Interior, Bureau of Ocean Energy Management, Regulation and Enforcement, Alaska OCS Region, Anchorage, Alaska.

NOAA (National Oceanic and Atmospheric Administration). 1978. Environmental assessment of the Alaskan Continental Shelf. Washington, D.C.: U.S. Department of Commerce.

Norton, D.W. 2001a. Down through time: Editor's introduction. In: Norton, D.W., ed. Fifty more years below zero. Fairbanks, Alaska: Arctic Institute of North America. 1-6.

— , ed. 2001b. Fifty more years below zero. Fairbanks, Alaska: Arctic Institute of North America. 576 p.

NRC (National Research Council). 2003. Cumulative environmental effects of oil and gas activities on Alaska's North Slope. Washington, D.C.: National Academies Press.

Reed, J.C. 1958. Exploration of Naval Petroleum Reserve No. 4 and adjacent areas, northern Alaska, 1944-53. Part 1, History of the exploration. Geological Survey Professional Paper 301. Washington, D.C.: U.S. Department of the Navy, Office of Naval Petroleum and Oil Shale Reserves.

Schindler, J.F. 2001. Naval Petroleum Reserve No. 4 and the beginnings of the Arctic Research Laboratory (ARL). In: Norton, D.W., ed. Fifty more years below zero. Fairbanks, Alaska: Arctic Institute of North America. 29-32.

Truett, J.C., and Johnson, S.R. 2000. The natural history of an Arctic oil field: Development and the biota. New York: Academic Press.

\section{APPENDIX: NORTH SLOPE SCIENCE INITIATIVE MEMBER AGENCIES AND ORGANIZATIONS.}

- Alaska Department of Fish and Game

- Alaska Department of Natural Resources

- Arctic Research Commission

- Arctic Slope Regional Corporation

- Bureau of Land Management

- Bureau of Ocean Energy, Management, Regulation, and Enforcement (previously Minerals Management Service)

- National Oceanic and Atmospheric Administration, National Marine Fisheries Service

- National Oceanic and Atmospheric Administration, National Weather Service

- National Oceanic and Atmospheric Administration, National Climate Service (proposed)

- National Park Service

- North Slope Borough

- U.S. Department of Energy

- U.S. Fish and Wildlife Service

- U.S. Geological Survey

Bill Streever is with BP Exploration (Alaska) Inc., Anchorage, Alaska; R. Suydam and T. Sformo are with the North Slope Borough Department of Wildlife Management in Barrow, Alaska; J.F. Payne, S. Guyer, and J.J. Taylor are with the North Slope Science Initiative in Anchorage; $R$. Shuchman is at Michigan Tech Research Institute, Ann Arbor, Michigan; R.P. Angliss and S.E. Moore are at the National Marine Mammal Laboratory, Alaska Fisheries Science Center, National Marine Fisheries Service, Seattle, Washington; Greg Balogh is with the Arctic Landscape Conservation Cooperative, U.S. Fish and Wildlife Service (USFWS), Anchorage; J. Brown lives in Woods Hole, Massachusetts; J. Grunblatt, D.L. Kane, J.J. Kelley, and G. Kofinas are with the University of Alaska - Fairbanks; D.R. Lassuy is with the USFWS, Anchorage; W. Loya is with the Wilderness Society, Anchorage; P. Martin is with the Arctic Landscape Conservation Cooperative, USFWS, Fairbanks; W.S. Pegau is with the Oil Spill Recovery Institute in Cordova, Alaska; C. Rea works for ConocoPhillips, Anchorage; D.J. Reed is with the Alaska Department of Fish and Game (ADFG), Nome, Alaska; M. Sturm is with USA-CRREL-Alaska, Ft. Wainwright, Alaska; T. Viavant is with ADFG in Fairbanks; $D$. Williams is with the Bureau of Ocean Energy Management, Anchorage; and D. Yokel is with the Bureau of Land Management's Arctic Field Office in Fairbanks. The corresponding author is Bill Streever: Bill.Streever@bp.com. 